\title{
Inverse Optimization based Detection of Leaks from Simulated Pressure in Water Networks, Part 1: Analysis for a Single Leak
}

\author{
Peace K. Amoatey, ${ }^{1}$ András Bárdossy ${ }^{2}$ and Heidrun Steinmetz ${ }^{3}$ \\ ${ }^{1}$ University of Ghana, Legon Accra, Ghana; ${ }^{2}$ University of Stuttgart, Stuttgart, Germany; ${ }^{3}$ Technische Universität Kaiserslautern, Kaiserslautern,
} Germany.

\begin{abstract}
The ability to easily detect leaks in water networks enables prompt repairs thereby reducing the duration of a leak. This study uses a minimization approach related to the Monte Carlo method to detect leakage in water networks that do not have continuous real time pressure-measuring systems, using a hydraulic model of the network. The model works very well in detecting leaks occurring in a gridded network while it performs below average for leaks occurring in branched areas. Reference pressures are obtained by introducing a leak of known magnitude into the network model by changing the emitter coefficient of a reference node. Reference pressures are compared with several simulated pressures from randomly simulated leaks. The leaking node is found as the most frequent node-emitter-coefficient combination for which the objective function is minimised. A minimum of eight reference points is required for a leak to be detected in any part of the network.
\end{abstract}

\section{Introduction}

Leaks are responsible for a significant portion of water losses in many water distribution systems. Water utilities seek to reduce the incidence of leakage in order to reduce the volume of water lost. One way this can be achieved is to reduce the duration of leaks. The duration of a leak is the total time it takes to detect, locate and repair the leak. During repairs, part of the network has to be shut down or isolated and this can disrupt supply (Palau et al. 2012). To minimize losses, it is necessary that the water utility has a tool to identify leakage points so it knows exactly which valves have to be shut for repairs. Modeling leak detection therefore aims to predict leakage points in order to reduce the response time between pipe failure and repair (Palau et al. 2012).

Many water utilities practice active leakage control, in which a search for leaks is undertaken using equipment that works mainly on acoustic principles. The use of such equipment and technology is much more effective and less time-consuming if the area where a leak could occur is predicted or known. Several different methods to predict leakage nodes within water networks are described in the literature. The fundamental idea is that a leak at a node is likely to be within pipes connected to the node (Trifunović et al. 2009; Wu and Sage 2006).

Leakage detection modeling has been the focus of many studies for about three decades. Non-acoustic methods such as direct transient methods (DTM), inverse transient methods (ITM) (Brunone 1999; Covas and Ramos 1999; Liggett and Chen 1994), probabilistic methods (Poulakis et al. 2003; Vanik et al. 2000) and pattern recognition methods (PRM) (De Silva et al. 2011; Gertler et al. 2010; Mashford et al. 2009; Caputo and Pelagagge 2003) have been investigated. These methods have yielded interesting results in water pipelines (Mashford et al. 2009), oil and gas pipelines (Wan et al. 2012; Li and Li 2010; Isa and Rajkumar, 2009; Da Silva et al. 2005) oil and refinery pipelines (Caputo and Pelagagge 2003), and in detecting leakage in complex networks other than a single pipeline with the transient methods (DTM and ITM). Additionally, these methods have detected up to $98 \%$ of all simulated leaks within $300 \mathrm{~m}$ (Mashford et al. 2009) and $150 \mathrm{~m}$ (Mirats-Tur et al. 2014) of the actual leak location, although with the help of sensors. We believe the range of leak detection can be improved on even without sensors installed. This is what this paper seeks to prove.

Direct transient modeling of pressures and flows has been extensively studied by Shucksmith (2011), Colombo et al. (2009), Karney et al. (2008), Vitkovsky et al. (2007), Wu and Sage (2006) and Wang et al. (2002). DTM involves creating pressure transients (pressure waves) by the sudden interruption to a section of the water network from shutting down or opening valves (Bru-none and Ferrante 2001; Brunone 1999; Covas and Ramos 1999; Liggett and Chen 1994). The transients propagate signals which are reflected in the presence of a leak. The reflected signal and its arrival time are measured to find the position of the leak. Though this is a simple method, it requires some experience to distinguish the pressure signals caused by a leak from other wave producing disturbances such as noise in the surroundings (Shucksmith 2011; Colombo et al. 2009; Karney et al. 2008; Vitkovsky et al. 2007).

To overcome some of the challenges of DTM, Wu et al. (2011), Karney et al. (2009), Kapelan et al. (2003), Vitkovsky et al.

Amoatey, Peace K., András Bárdossy and Heidrun Steinmetz. Inverse Optimization based Detection of Leaks from Simulated Pressure in Water Networks, Part 1: Analysis for a Single Leak. Journal of Water Management Modeling 26: C460. doi: 10.14796/JWMM.C460. (c) CHI 2018. www.chijournal.org ISSN 2292-6062. 
(2001) and Covas et al. (2001) have studied injected hydraulic transients of known intensity at a given location. The pressure signals obtained as a result of the hydraulic transient are recorded at pre-determined locations within the network. With the help of solvers that use optimization routines, such as the genetic algorithm, the Levenberg-Marquardt algorithm and the shuffled complex evolution approach, the leak location is determined. The method is computationally burdensome and time consuming when applied to an entire network (Vitkovsky et al. 2007).

Bayesian modeling uses flow test data to provide estimates of the most probable leakage events (magnitude and location of leakage) and the uncertainties in such estimates (Poulakis et al. 2003; Vanik et al. 2000).

Multivariate statistical pattern recognition methods (PRMs) have been introduced into leakage detection research. This approach identifies patterns in the negative pressure wave and builds a classification system of the wave structure to effectively distinguish between normal adjustment states and leakage states (Wan et al. 2012; Li and Li 2010). It has been used for leak detection in water networks as well as in the oil and gas industry (Da Silva et al. 2005). PRMs include fuzzy logic (Da Silva et al. 2005; De Silva et al. 2011), artificial neural networks (Caputo and Pelagagge 2003), support vector machines (De Silva et al. 2011; Mashford et al. 2009) and principal component analysis (Nowicki and Grochowski 2011; Gertler et al. 2010). These techniques can be applied to an entire network and have been known to locate $\sim 98 \%$ of leaks within $300 \mathrm{~m}$ of the actual leak. However, these results were achieved with the help of sensors in the distribution network. Most developing countries do not have sensors installed within the network and so may not be able to utilize these methods.

Jasper et al. (2013) used simulation-optimization inverse modeling to detect leaks in the water network. In their study, the differences between the real and simulated pressure measurements are minimized for a leak to be found. This was possible because the pressure was continuously measured within the network. Again, not all networks, especially in developing countries, have continuous pressure measurement and so might not be able to utilize this method.

Mirats-Tur et al. (2014) applied two methods based on the sensitivity analysis of pressure measurements relative to the demand variation at any node in the distribution system. They ob-tained similar results for both methods. Leaks were located within $150 \mathrm{~m}$ of the actual leak. Ishido and Takahashi (2014) introduced a new algorithm for real time leak detection which uses a head loss ratio (HLR), which is the ratio of two differences of pressure mea-surements, as an indicator for burst leaks in a water distribution network. The authors found that the method can be successfully applied to a wider class of water distribution networks. Sousa et al. (2015) developed an optimization model that minimized the differences between estimated and measured pressures at the monitoring points to identify leaky pipes.
The objective function was solved by a simulated annealing algorithm and was found to be reliable, fast and easy to implement. The results obtained for a single leak or for two simultaneous leaks at different locations are very encouraging.

The leak detection modeling described in this study is similar in some ways to the work of Sousa et al. (2015), Ishido and Takahashi (2014), Jasper et al. (2013), Karney et al. (2009), Mashford et al. (2009) and Wu and Sage (2006). A leak is simulated by introducing transients of known magnitude into a water network (Karney et al. 2009; Wu and Sage 2006) by altering the emitter coefficient (Mashford et al. 2009) of a node within the network and using an inverse modeling approach to locate the leak (Jasper et al. 2013).

The difference is that while Mashford et al. (2009) simulated leaks in the network by increasing the value of the emitter coeffi-cient from 0.000 to 0.3 in steps of 0.002 , in this study we simulate leaks by randomly changing the value of the emitter coefficient between 0.1 and 0.3 . This is a preliminary step to test the ability of the model to detect leaks in the case study water network, which is not equipped with sensors. Smaller leak sizes were later tested, the results of which will be published later. In this study, the inverse optimization approach minimizes pressure differences between reference and simulated pressures instead of between simulated and real pressure measurements as described by Jas-per et al. (2013) or between estimated and measured pressures as described by Sousa et al. (2015).

Our approach makes this study suitable for networks in developing countries where historical data do not exist and sensors are not installed for continuous monitoring. This modeling approach inverts the Monte Carlo method, whereby a leak of known magnitude is introduced at a selected node and inversely detected from several runs with randomly simulated pressures. We investigate whether the model can detect a leaking node with a leak size in the range indicated above. Furthermore, we explore how many reference or measurement points are required for a leaking node to be detected. The modeling for simulating leaks was carried out using the water distribution network of Baifikrom, Ghana as a case study.

\section{Methodology: Inverse Monte Carlo Modeling}

The leak simulation approach of changing the emitter coefficient of a network node in order to simulate pressures in this study is in some way similar to the approaches of Mashford et al. (2009) and Jasper et al. (2013). Amoatey (2015) used this method to simulate pressures; however, the leak is detected using an inverse optimization approach similar to that used by Jasper et al. (2013). This automated process of simulating several runs of pressures in the network hydraulic model is illustrated in Figure 1 (Amoatey 2015). 


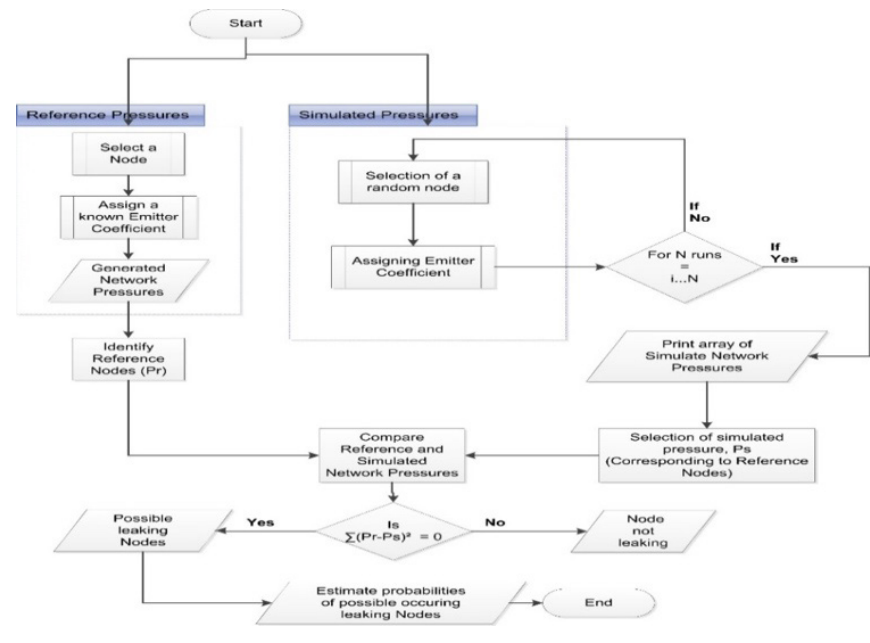

Figure 1 Leakage detection modeling workflow (Amoatey 2015).

The method has three steps. First, a reference node is assigned a leak of known magnitude. This was done by changing the emitter coefficient of the node and running the model. The reference pressures $P_{r}$ generated at selected reference nodes (representing measurement points) are noted. Subsequently, the model randomly selects a node, randomly assigns an emitter coefficient to the selected node and generates nodal pressure throughout the network. This simulation process was consequently automated to carry out several model runs to obtain simulated pressures $P_{s}$.

The two sets of pressures (reference pressures $P_{r}$ and simulated pressures $P_{s}$ ) are compared for the selected reference nodes or points. The sum of squared errors must be zero for a leak node to be detected.

\subsection{Simulating Pressures in Water Network}

To introduce a leak unto a network in a hydraulic model, the emitter property of a network node is modified. An emitter coefficient is equivalent to a leak flow rate and running the model generates pressures for all other nodes in the network. This relationship is described by Equations 1 and 2 (Mashford et al. 2009; Trifunović et al. 2009; Tabesh et al. 2009). The method was automated to randomly generate several pressures which are compared to the pressures generated by the leak of known magnitude.

$$
E C=Q / P^{\alpha}
$$

thus

$$
Q=E C * P^{\alpha}
$$

where:

$$
\begin{aligned}
E C & =\text { emitter coefficient }\left(\mathrm{L} / \mathrm{s} / \mathrm{m}^{\alpha}\right) \\
P & =\text { nodal pressure }(\mathrm{m}), \\
a & =\text { EPANET exponent for pressure, and }
\end{aligned}
$$

$$
Q=\text { leak flow rate }(\mathrm{L} / \mathrm{s}) \text {. }
$$

\subsection{Detection of a Leaking Node}

The idea is to identify nodes within the network with assigned emitter coefficients that generate pressures similar to those of the reference leaking nodes with their assigned emitter coefficients. The mathematical notation of the model is given by:

$$
S S=\operatorname{diag}\left[\left(Y-J_{n} \tilde{x}\right)\left(Y-J_{n} \tilde{x}\right)^{\prime}\right]=\text { vector of dimension } n
$$

where:

$$
\begin{aligned}
\text { SS } & =\text { sum of squares, which is equal to } 0, \\
Y & =\text { an } n \times p \text { matrix } \\
\tilde{x} & =\text { vector of simulated pressures, } \\
J_{n} & =\text { an } n \times 1 \text { vector of ones, } \\
n & =\text { number of model runs, and } \\
p & =\text { number of reference points. }
\end{aligned}
$$

As this is an optimization approach, a leak is detected when the objective function yields a sum of squares equal to zero for the reference and simulated pressures, as given by Sousa et al. (2015) and Jasper et al. (2013):

$$
S S E=\sum_{i=1}^{n}\left(P_{r}-P_{s}\right)^{2}=0
$$

where:

$$
\begin{aligned}
S S E & =\text { sum of squared errors } \\
P_{r} & =\text { reference pressures at the of known leak, } \\
P_{s} & =\text { simulated nodal pressures, and } \\
n & =\text { number of runs. }
\end{aligned}
$$

\section{Application of Inverse Modeling of Sim- ulated Leaks to Case Study Network}

The case study water network is served from a water treatment plant located at Baifikrom, near Mankessim in the central region of Ghana. The network is bounded by latitudes $5^{\circ} 9^{\prime} 30^{\prime \prime} \mathrm{N}-5^{\circ} 19^{\prime} 0^{\prime \prime} \mathrm{N}$ and longitudes $0^{\circ} 58^{\prime} 30^{\prime \prime} \mathrm{W}-1^{\circ} 9^{\prime} 30^{\prime \prime} \mathrm{W}$ (AVRL 2008). The Baifikrom water network is one of eight separate distribution systems of the Ghana Water Company in the Central Region of Ghana. The water network was first built in 1960 and was rehabilitated and expanded to a design capacity of $12000 \mathrm{~m}^{3} / \mathrm{d}$ in 2008 to meet projected demand until 2020.

The network serves a population of about 122000 (AVRL 2008; Ghana Statistical Service (2001)) in 32 urban and rural communities covering an area of $\sim 250 \mathrm{~km}^{2}$. The network has $\sim 300$ nodes and 315 pipes of total length $\sim 150 \mathrm{~km}$. The per capita design consumption rates range from $30 \mathrm{~L} / \mathrm{d}$ to $75 \mathrm{~L} / \mathrm{d}$ (AVRL 2008). Total demand is $318 \mathrm{~m}^{3} / \mathrm{h}$. Pipes are made of asbestos cement (AC), high density polyethylene (HDPE) or polyvinyl chloride (PVC).

To use the inverse modeling approach described above for the case study water network, two scenarios were considered: 
a leak at a node (No76) in a branched pipe serving Saltpond Township; and a leak at a node (No152) found in a dense area within Mankessim Township. These two nodes were selected as reference (leaking) nodes.

Leaks of $2 \mathrm{~m}^{3} / \mathrm{h}$ to $6 \mathrm{~m}^{3} / \mathrm{h}$, which are equivalent to emitter coefficients in the range $0.1 \mathrm{~L} / \mathrm{s} / \mathrm{m}$ to $0.3 \mathrm{~L} / \mathrm{s} / \mathrm{m}$, were randomly assigned. No76 was assigned a leak with emitter coefficient 0.2994 while No152 was assigned emitter coefficient 0.253 . Four reference nodes (No38, No108, No156 and No255) were selected. Reference pressures at the four selected reference nodes were recorded for comparison with several randomly simulated pressures at the same points (see Figure 2). This selection was later increased to six (P103 and P333 added), eight (P207 and P266 added) and ten (P179 and P213 added) reference points from different parts of the network to observe the behavior of the model for ease of identifying the leaking node. The reference points and nodes are shown in Figure 2.

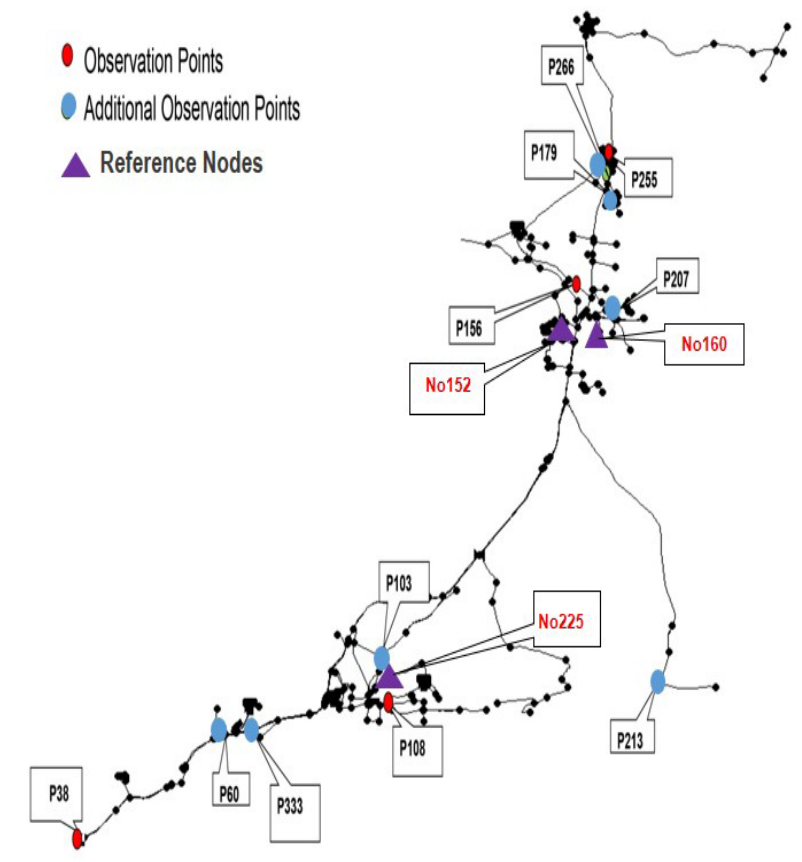

Figure 2 Map showing reference points (modified from Amoatey 2015).

To ensure a high confidence level and complete distribution for the performance of the simulation output (Ritter et al. 2010), simulation runs of 5000 and 10000 iterations were carried out. This was done to allow each of the nearly 300 nodes in the network to combine several times with each of the different emitter coefficients. Nodes that are assigned emitter coefficients in which the objective functions are minimized were identified. The identified nodes were further studied to determine whether they are in any way connected to No76 and No152. Such nodes are identified as likely leaking nodes. The model runs quickly and is computationally less demanding than some of the methods discussed earlier.

\section{Results: Model Performance Evaluation}

The results for the two scenarios that were considered are given. The results are organized based on leaks occurring in branched pipes and leaks in gridded pipes within the water network. The investigation for each scenario concentrated on a link between the number of runs and the leak detection rate. Given 5000 simulation runs and $\sim 300$ nodes in the network, each node could occur $\geq 16$ times. Similarly, the model should randomly select a node and assign a leak coefficient $\geq 33$ times in the 10000 simulation runs. The model detects the leaking node as the node that is assigned the highest value of the emitter coefficient. The probabilities of the nodes occurring were computed. Generally, the results show that the solution to this optimization problem is not unique in both scenarios.

\subsection{Leak in a Branched Pipe (No76)}

In this scenario, comparison of randomly simulated pressures with reference pressures yielded very interesting results. For 5000 simulation runs, 61 of them had SSE equal to zero, which implies that all 61 nodes with assigned emitter coefficients showed similar pressures as a leak with emitter coefficient of 0.2994 at No76. These 61 functions occurred on three nodes, No76, No87 and No97. Thus, these are likely the leaking nodes. However, No87 and No97 are $200 \mathrm{~m}$ and $\sim 400 \mathrm{~m}$ away from No76 and are directly connected to the test node No76 (see Figure 3). The most occurring node was No76 (22 out of 61), followed by No97 (20 out of 61) and No87 (19 out of 61) making No76 the most highly probable leaking node even though the probability is relatively low ( 30\%).

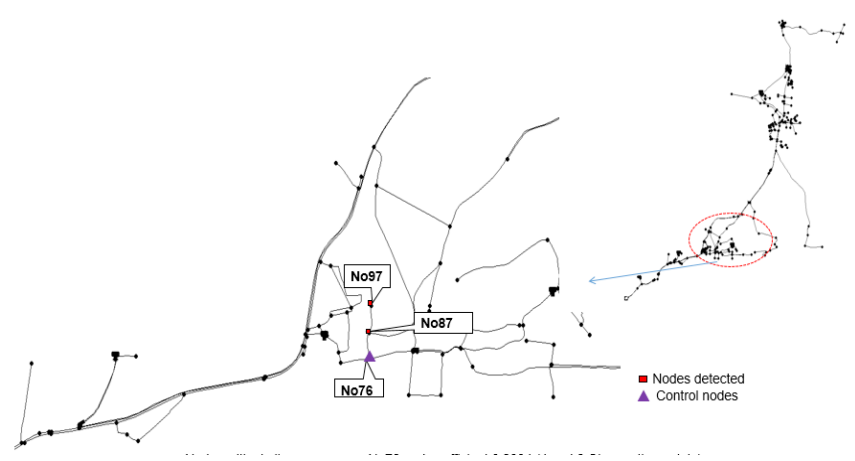

Figure 3 Nodes detected together with No76 using 4 and 6 reference points (Amoatey 2015).

Interestingly, with increased numbers of reference points (six, eight and ten) the results remained the same, indicating that there is no improvement in identifying and locating the leaking node even if the number of reference points is increased beyond four. Thus, for highly branched networks (not looped or gridded), four reference points are adequate for a leak to be detected. It can therefore be inferred that in future, the placement of sensors in a branched network can be optimized and four sensors would be adequate. It can additionally be inferred that nodes connected to or around the modeled leaking node (control node and emitter 
coefficient) are likely to show similar pressures as the leaking node.

With 10000 simulation runs, SSE between the reference pressure and randomly selected pressures at four reference points is zero in 117 cases. Again, No76, No87 and No97 emerged as likely (possible) leaking nodes, which implies that all leak coefficients on these nodes gave the same pressures as No76, 0.2994. In this case, however, No76 had the least probability of occurrence with 35 out of 117 functions while No87 and No97 had 37 and 45 leaks out of 117 . The resulting probabilities of minimized objective functions are summarized in Table 1.

Table 1 Resulting probability of branched leaking node.

\begin{tabular}{ccccccc}
\hline $\begin{array}{c}\text { Control leak- } \\
\text { ing node }\end{array}$ & $\begin{array}{c}\text { Reference } \\
\text { points }\end{array}$ & $\begin{array}{c}\text { Likely leak- } \\
\text { ing nodes }\end{array}$ & $\begin{array}{c}\text { Out of 5000 } \\
\text { runs (\%) }\end{array}$ & $\begin{array}{c}\text { Resulting } \\
\text { nodes }\end{array}$ & $\begin{array}{c}\text { Resulting } \\
\text { counts }\end{array}$ & $\begin{array}{c}\text { Resulting } \\
\text { probabilities }\end{array}$ \\
\hline No76 & $4,6,8$ and 10 & 61 & 1.22 & No76 & 22 & 0.361 \\
& & & & No87 & 19 & 0.311 \\
& & & & No97 & 20 & 0.328 \\
\hline Control leak- & Reference & Likely leak- & Out of 10 000 & Resulting & Resulting & Resulting \\
ing node & points & ing nodes & runs (\%) & nodes & counts & probabilities \\
\hline \multirow{2}{*}{ No76 } & $4,6,8$ and 10 & 117 & 1.17 & No76 & 35 & 0.299 \\
& & & & No87 & 37 & 0.316 \\
& & & & No97 & 45 & 0.385 \\
\hline
\end{tabular}

As in the 5000 run case, the results were the same when the number of measurements or number of reference points were increased. Thus, in a branched network, the ability of the model to detect leaking nodes is quite poor. Increasing the simulation runs does not improve the probability of identifying the leaking node. Moreover, increasing the number of reference points does not in-crease the detectability of the leaking node. However, since No76 is only $200 \mathrm{~m}$ and $400 \mathrm{~m}$ away from No87 and No97, it is not too laborious to find the leak even though further research is needed to increase the range of the distance within which a leak is detect-ed by the model. This has implications for further research as the detectability of the model needs to be improved to enhance leak detection on the branched network. This is necessary since the case study network, like other networks, has branched sections as well as gridded sections.

\subsection{Leak in a Pipe in a Gridded Area (No152)}

In this scenario, No152, which is situated in a dense part of the network, was connected to several other nodes. For 5000 simulation runs and 4 and 6 reference points, SSE was zero in 243 cases involving 18 nodes which were either directly connected to or around No152, as shown in Figure 4. No285, which is $300 \mathrm{~m}$ away from No152 (the leaking node) had the highest probability followed by No152.

When the number of reference points was increased to 8 and 10, SSE was zero in 22 cases involving 2 nodes, as shown in Figure 5. No152 occurred 19 times (highest probability) with different coefficients while No155 occurred 3 times, as shown in Table 2.

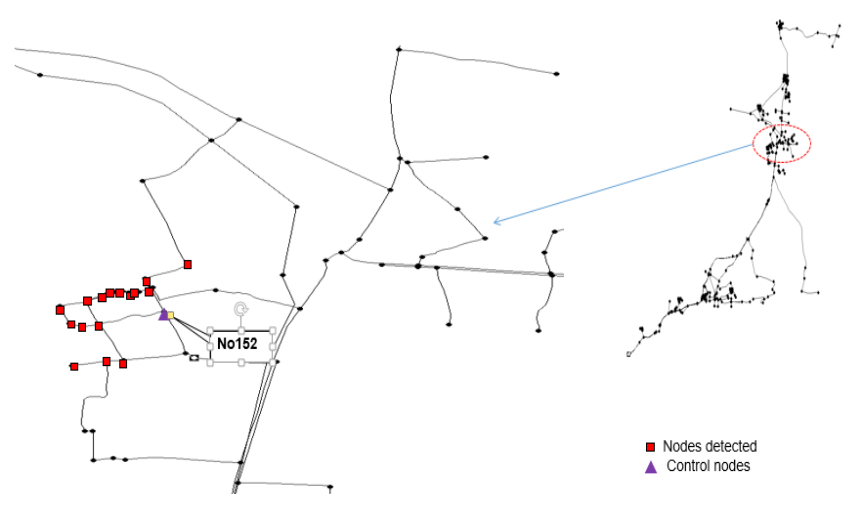

Figure 4 Nodes detected together with No152 using 4 and 6 reference points (Amoatey 2015).

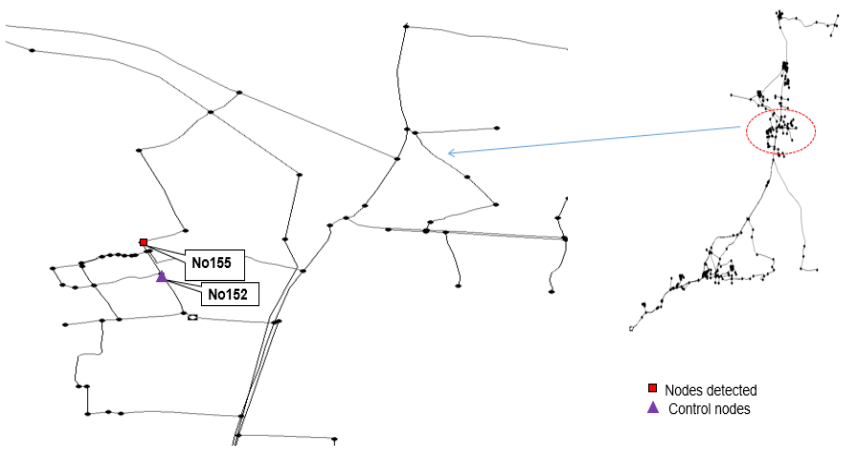

Figure 5 Nodes detected together with No152 using 8 and 10 reference points (Amoatey 2015).

Table 2 Resulting probability of gridded leaking node (5000 runs).

\begin{tabular}{|c|c|c|c|c|c|c|}
\hline $\begin{array}{l}\text { Control leak- } \\
\text { ing node }\end{array}$ & $\begin{array}{c}\text { Reference } \\
\text { points }\end{array}$ & $\begin{array}{c}\text { Likely leaking } \\
\text { nodes }\end{array}$ & $\begin{array}{c}\text { Out of } 5000 \\
\text { runs (\%) }\end{array}$ & $\begin{array}{c}\text { Resulting } \\
\text { nodes }\end{array}$ & $\begin{array}{c}\text { Resulting } \\
\text { counts }\end{array}$ & $\begin{array}{c}\text { Resulting } \\
\text { probabilities }\end{array}$ \\
\hline \multirow{20}{*}{ No152 } & \multirow[t]{18}{*}{4 and 6} & \multirow[t]{18}{*}{243} & \multirow[t]{18}{*}{4.86} & No143 & 11 & 0.045 \\
\hline & & & & №147 & 18 & 0.074 \\
\hline & & & & No149 & 10 & 0.041 \\
\hline & & & & No151 & 18 & 0.074 \\
\hline & & & & No152 & 19 & 0.078 \\
\hline & & & & No153 & 13 & 0.053 \\
\hline & & & & No154 & 18 & 0.074 \\
\hline & & & & No155 & 15 & 0.062 \\
\hline & & & & No285 & 21 & 0.086 \\
\hline & & & & No295 & 15 & 0.062 \\
\hline & & & & No296 & 5 & 0.021 \\
\hline & & & & No297 & 8 & 0.033 \\
\hline & & & & No298 & 6 & 0.025 \\
\hline & & & & No299 & 1 & 0.004 \\
\hline & & & & No302 & 17 & 0.070 \\
\hline & & & & No303 & 14 & 0.058 \\
\hline & & & & No304 & 17 & 0.070 \\
\hline & & & & No306 & 17 & 0.070 \\
\hline & \multirow[t]{2}{*}{8 and 10} & \multirow[t]{2}{*}{22} & \multirow[t]{2}{*}{0.44} & No152 & 19 & 0.864 \\
\hline & & & & No155 & 3 & 0.136 \\
\hline
\end{tabular}


In the network, No155 is $400 \mathrm{~m}$ away from No152 but not on the same pipe. Since each node can be randomly assigned a leak at least sixteen times and No152 occurred nineteen times, it can be safely inferred that No152 is the leaking node. Thus, for a leak in a gridded network, the number of reference points should be $\geq 8$ for a leak to be located. The ability of the model to detect a leak is thus, much better for a gridded network or for nodes which are highly connected to other nodes. The interactions between pressures generated on surrounding nodes as a result of the leak within such a network are quite complex and it requires more reference points to identify the leaking node.

For 10000 simulation runs, as in the previous scenario, the objective function was minimized in 485 cases with 4 and 6 reference points. Again, these occurred on 18 nodes as in the 5000 runs. No154 had the highest probability of occurrence among the possible leaking nodes. This is followed by No151 and before the reference leaking No152, making identification of the leaking node challenging. Subsequently, the reference points were increased to 8 and 10. The resulting objective functions which were minimized reduced to 42 . The likely leaking nodes were 3 , as in the case of 5000 runs (see Figure 5). In this case, No152 had the highest probability (86\%) of occurrence. These results are summarized in Table 3.

Table 3 Resulting probability of gridded leaking node (10 000 runs).

\begin{tabular}{|c|c|c|c|c|c|c|}
\hline $\begin{array}{l}\text { Control leak- } \\
\text { ing node }\end{array}$ & $\begin{array}{c}\text { Reference } \\
\text { points }\end{array}$ & $\begin{array}{l}\text { Likely leak- } \\
\text { ing nodes }\end{array}$ & $\begin{array}{c}\text { Out of } 10000 \\
\text { runs (\%) }\end{array}$ & $\begin{array}{c}\text { Resulting } \\
\text { nodes }\end{array}$ & $\begin{array}{c}\text { Resulting } \\
\text { counts }\end{array}$ & $\begin{array}{c}\text { Resulting } \\
\text { probabilities }\end{array}$ \\
\hline \multirow{21}{*}{ No152 } & \multirow[t]{18}{*}{4 and 6} & \multirow[t]{18}{*}{485} & \multirow[t]{18}{*}{4.85} & №143 & 20 & 0.041 \\
\hline & & & & No147 & 35 & 0.072 \\
\hline & & & & No149 & 22 & 0.045 \\
\hline & & & & No151 & 37 & 0.076 \\
\hline & & & & No152 & 36 & 0.074 \\
\hline & & & & No153 & 33 & 0.068 \\
\hline & & & & No154 & 41 & 0.085 \\
\hline & & & & №155 & 31 & 0.064 \\
\hline & & & & №285 & 32 & 0.066 \\
\hline & & & & No295 & 29 & 0.060 \\
\hline & & & & №296 & 11 & 0.023 \\
\hline & & & & №297 & 14 & 0.029 \\
\hline & & & & No298 & 9 & 0.019 \\
\hline & & & & No299 & 3 & 0.006 \\
\hline & & & & No302 & 31 & 0.064 \\
\hline & & & & No303 & 29 & 0.060 \\
\hline & & & & No304 & 33 & 0.068 \\
\hline & & & & №306 & 38 & 0.078 \\
\hline & \multirow[t]{3}{*}{8 and 10} & \multirow[t]{3}{*}{42} & \multirow[t]{3}{*}{0.42} & No152 & 36 & 0.857 \\
\hline & & & & No155 & 5 & 0.119 \\
\hline & & & & No149 & 1 & 0.024 \\
\hline
\end{tabular}

It is reiterated that for leaks in gridded networks, a minimum of 8 reference points is necessary for leak detection. Since each node occurred at least 33 times, leaks of practically all leak sizes on No152 within the range tested $\left(2 \mathrm{~m}^{3} / \mathrm{h}\right.$ to $\left.6 \mathrm{~m}^{3} / \mathrm{h}\right)$ yield the same pressures as an emitter coefficient of 0.253 on No152. For leaks in a gridded part of the network, increasing the number of simulation runs increased the capability of the model to detect leaks. Increasing the number of reference pressure points to at least 8 improved the accuracy of detection and location of the leak.

The results obtained are similar to those obtained by Mashford et al. (2009) who identified $98 \%$ of simulated leaks within $300 \mathrm{~m}$ of the leaking node. However, this model requires improvement if compared with the outcome of Mirats-Tur et al. (2014), who located leaks within $150 \mathrm{~m}$ of the actual leak. Since $100 \%$ of all likely leaking nodes can be found within $400 \mathrm{~m}$ of the modeled leaking node, it can be inferred that the model performs well and that it is not too difficult to find and repair leaks, especially in water networks in developing countries. Together with our use of a hydraulic model, the inverse optimization application to the Monte Carlo simulation of network pressures described in this paper is suitable even for networks without sensors, unlike the studies of Mirats-Tur et al. (2014) and Jasper et al. (2013). It is also mathematically easy and computationally fast. However, the model has to be further studied for a set tolerance of, say, SSE $<0.05$, since calibration of the network model may not be $100 \%$ perfect as the network is in real time. This will further inform how well the model needs to be calibrated to perform well and ascertain what the limitations may be on using our leak detection approach.

Table 4 gives a summary of the model performance for all the scenarios considered using ten reference points.

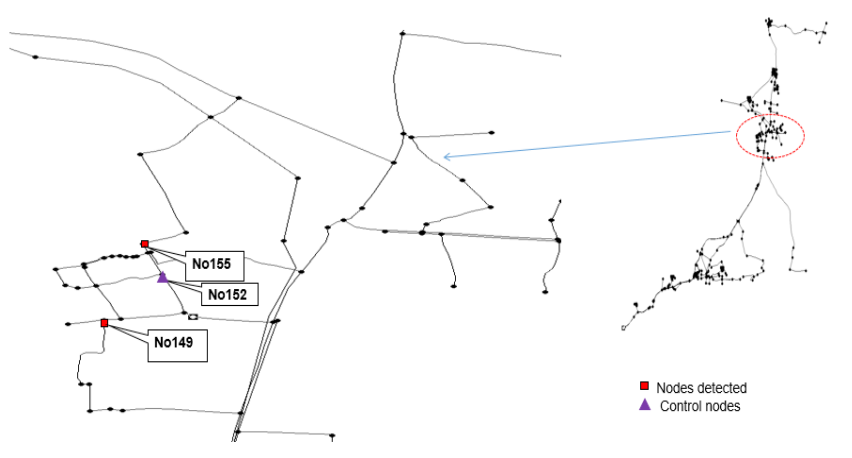

Figure 6 Nodes detected together with No152 using 8 and 10 reference points (Amoatey 2015).

Table 4 Summary results of model performance.

\begin{tabular}{lcccl}
\hline \multicolumn{1}{c}{ No. of leaks } & Scenarios & No. of runs & Performance & \multicolumn{1}{c}{ Remark on performance } \\
\hline One leak & Branched & $5000 \& 10000$ & $36 \& 30 \%$ & Does not improve with increased \\
(big leak size) & network & & & number of reference points \\
& $\begin{array}{l}\text { Gridded } \\
\text { network }\end{array}$ & $5000 \& 10000$ & $7 \% \& 86 \%$ & $\begin{array}{l}\text { Improved with higher number of } \\
\text { reference points (8 and 10) }\end{array}$ \\
& & & efence \\
\hline
\end{tabular}

\section{Conclusion}

This study developed an optimization approach to aid leak detection in water networks in developing countries. Such networks do not have adequate equipment and technology such as continuous pressure measurement and sensors to detect leaks within the 
network. We used inverse modeling of the Monte Carlo method where a leak of known magnitude is put on a node and the model attempts to find it by the minimization of reference and simulated pressures. For a leak occurring on a branched pipe the model performed below average (36\%) while it performed very well (86\%) for a leak in a gridded network. Differences between the two types are found in the number of reference points needed.

The investigation clearly showed that four reference points are required for the leak in the branched part of the network to be detected while a minimum of eight reference points is required for a leak in the gridded part of the network. This information helps to improve modeling and siting equipment for measurement as well as the installation of sensors in the network. This will enable water utilities to optimize measurement points in the network for easy leakage detection. In Paper 2 (Amoatey et al. 2018), the ability of the model approach described in this paper to simultaneously detect two leaks in the network is reported. Further work will include investigating if the model detects relatively smaller leak sizes than the range considered in this paper.

\section{References}

Amoatey, P. K. 2015. Leakage Management in the Urban Water System in Ghana: Estimation and Detection Modelling. Stuttgart: University of Stuttgart. PhD dissertation. ISBN 978-3-83567291-8.

https://stg.ibs-bw.de/aDISWeb/app?service=direct/0/ Home/\$DirectLink\&sp=S127.0.0.1:23022\&sp=SAKSWB-IdNr470460091

Amoatey, P. K., A. Bárdossy and H. Steinmetz. 2018. “Inverse Optimization based Detection of Leaks from Simulated Pressure in Water Networks, Part 2: Analysis for Two Leaks." Journal of Water Management Modeling 26: C461. doi: 10.14796/JWMM.C461.

AVRL (Aqua Vitens Rand Limited). 2008. Network Design Report. AVRL Report 1-44.

Brunone, B. 1999. “Transient Test Based Technique for Leak Detection in Outfall Pipes." Journal of Water Resources Planning and Management 125 (5): 302-6.

Brunone, B. and M. Ferrante. 2001. "Detecting Leaks in Pressurized Pipes by Means of Transients." Journal of Hydraulic Research 39 (5): 539-47.

Caputo, A. C. and P. M. Pelagagge. 2003. “Using Neural Networks to Monitor Piping Systems." Process Safety Progress 22 (2): 119-27.

Colombo, A. F., P. Lee and B. W. Karney. 2009. "A Selective Literature Review of Transient-Based Leak Detection Methods." Journal of Hydro-environment Research 2:212-27.

Covas, D. and H. Ramos. 1999. “Leakage Detection in Single Pipelines Using Pressure Wave Behavior." In Proceedings of the 5th International Conference on Computing and Control in the Water Industry (CCWI), Exeter, UK, 287-99. Exeter: University of Exeter, Centre for Water Systems.
Covas, D., I. Stoianov, D. Butler, C. Maksimovic, N. Graham and H. Ramos. 2001. “Leakage Detection in Pipeline Systems by Inverse Transient Analysis-From Theory to Practice." In Proceedings of the 6th International Conference on Computing and Control in the Water Industry (CCWI), Leicester, England.

Da Silva, H. V., C. K. Morooka, I. R. Guilherme, T. C. da Fonseca and J. R. P. Mendes. 2005. “Leak Detection in Petroleum Pipelines using a Fuzzy System." Journal of Petroleum Science and Engineering 49:223-238.

De Silva, D., J. Mashford and S. Burn. 2011. Computer Aided Leak Location and Sizing in Pipe Networks: Urban Water Security Research Alliance Technical Report No. 17, 2nd ed. Canberra, ACT: (CSIRO) Commonwealth Scientific and Industrial Research Organisation.

http://www.urbanwateralliance.org.au/publications/UWSRA-tr17.pdf

Gertler, J., J. Romera, V. Puig and J. Quevedo. 2010. “Leak Detection and Isolation in Water Distribution Networks using Principal Component Analysis and Structured Residuals." In 2010 Conference on Control and Fault Tolerant Systems, 191-6. New York: IEEE. https://doi.org/10.1109/SYSTOL.2010.5676043

Ghana Statistical Services. 2001. Population Census 2000. Accra: Government of Ghana.

Isa, D. and R. Rajkumar. 2009. “Pipeline Defect Prediction using Support Vector Machines." Applied Artificial Intelligence 23:758-71.

Ishido, Y. and S. Takahashi. 2014. "A New Indicator for Real-Time Leak Detection in Water Distribution Networks: Design and Simulation Validation." Procedia Engineering 89:411-7.

Jasper, M. N., G. Mahinthakumar, S. Ranjithan and E. D. Brill. 2013. "A Sensitivity Analysis of Data Measurement Types for Leak Detection in Water Distribution Systems." In World Environmental and Water Resources Congress, 2013, Cincinatti, Ohio, 611-6. Reston, VA: American Society of Civil Engineers. https://doi.org/10.1061/9780784412947.059

Kapelan, Z. S., D. A. Savic and G. A. Walters. 2003. “A Hybrid Inverse Transient Model for Leakage Detection and Roughness Calibration in Pipe Networks." Journal of Hydraulic Research 41 (5): 481-92.

Karney, B., D. Khani, M. R. Halfawy and O. Hunaidi. 2009. "A Simulation Study on Using Inverse Transient Analysis for Leak Detection in Water Distribution Networks." Journal of Water Management Modeling 17: R235-23. doi: 10.14796/JWMM.R235-23.

Karney, B., A. Parente, E. Eerkes and C. White. 2008. “Assessing Performance of a Water Transmission System Using an Inverse Transient Method." Proceedings Pipelines 2008:1-8.

Li, X. and G. J. Li. 2010. “Leak Detection of Municipal Water Supply Network Based on the Cluster-Analysis and Fuzzy Pattern Recognition. In Proceedings of International Conference on E-Product E-Service and E-Entertainment, Henan, China. New 
York: IEEE.

https://doi.org/10.1109/ICEEE.2010.5660550

Liggett, J. A. and L. C. Chen. 1994. "Inverse Transient Analysis in Pipe Networks." Journal of Hydraulic Engineering 120 (8): 934-55.

Mashford, J., D. De Silva, D. Marney and S. Burn. 2009. “An Approach to Leak Detection in Pipe Networks using Analysis of Monitored Pressure Values by Support Vector Machine." In Proceedings of the 2009 Third International Conference on Network and System Security, 534-9. New York: IEEE Explore. https://doi.org/10.1109/NSS.2009.38

Mirats-Tur, J. M., P.-A. Jarrige, J. Meseguer and G. Cembrano. 2014. "Leak Detection and Localization using Models: Field Results." Procedia Engineering 70:1157-65. https://doi.org/10.1016/j.proeng.2014.02.128

Nowicki, A. and M. Grochowski. 2011. “Kernel PCA in Application to Leakage Detection in Drinking Water Distribution System." In Proceedings of the Third International Conference on Computational Collective Intelligence: Technologies and Applications, 497-506. Berlin: Springer.

Palau, C. V., F. J. Arregui and M. Carlos. 2012. "Burst Detection in Water Networks Using Principal Component Analysis." Water Resources Planning and Management 138 (1): 47-54.

Poulakis, Z., D. Valougeorgis and C. Papadimitriou. 2003. “Leakage Detection in Water Pipe Networks using a Bayesian Probabilistic Framework." Probabilistic Engineering Mechanics 18:315-27.

Ritter, F. E., M. J. Schoelles, K. S. Quigley and L. C. Klein. 2010. “Determining the Number of Simulation Runs: Treating Simulations as Theories by not Sampling their Behaviour." In Human-in-the-loop Simulations: Methods and Practice edited by S. Narayanan and L. Rothrock, 97-116. Berlin: Springer:

Shucksmith, J. 2011. "Leak Detection using Pressure Transients." Presentation to the Water Industry Forum, Pennine Water Group, University of Sheffield.

Sousa, J., L. Ribeiro, J. Muranho and A. Sá Marques. 2015. “Locating Leaks in Water Distribution Networks with Simulated Annealing and Graph Theory." Procedia Engineering 119:63-71.
Tabesh, M., A. H. Asadiani Yekta and R. Burrows. 2009. "An Integrated Model to Evaluate Losses in Water Distribution Systems." Water Resources Management 23:477-92.

Trifunović, N., S. Sharma and A. Pathirana. 2009. "Modelling Leakage in Distribution System Using EPANET." Paper presented at the IWA Water Loss Conference, 2009, Cape Town, South Africa.

Vanik, M. W., J. L. Beck and S. K. Au. 2000. “Bayesian Probabilistic Approach to Structural Health Monitoring." Journal of Engineering Mechanics 126 (7): 738-45.

Vitkovsky, J. P., A. R. Simpson, M. F. Lambert and J. A. Liggett. 2007. "Experimental Observation and Analysis of Inverse Transients for Pipeline Leak Detection." Water Resources Planning and Management 133 (6): 519-30.

Vitkovsky, J. P., A. R. Simpson, M. F. Lambert and X. J. Wang. 2001. "An Experimental Verification of the Inverse Transient Technique for Leak Detection." In Proceedings of the Sixth Conference on Hydraulics in Civil Engineering: The State of Hydraulics, Hobart, Tasmania, 373-80. Barton, ACT: Institution of Engineers, Australia.

Wan, J., Y. Yu, Y. Wu, R. Feng and N. Yu. 2012. "Hierarchical Leak Detection and Localization Method in Natural Gas Pipeline Monitoring Sensor Networks." Sensors 12 (1): 189-214.

Wang, X. J., M. F. Lambert, A. R. Simpson, J. A. Liggett and J. P Vitkovsky. 2002. "Leak Detection in Pipelines using the Damping of Fluid Transients." Journal of Hydraulic Engineering 128 (7): 697-711.

Wu, Z. Y., M. Farley, D. Turtle, Z. Kapelan, J. Boxall, S. Mounce, S. Dahasahasra, M. Mulay and Y. Kleiner. 2011. Water Loss Reduction. Exton, PA: Bentley Institute Press.

Wu, Z. Y. and P. Sage. 2006. "Water Loss Detection via Genetic Algorithm Optimization-Based Model Calibration." In Eighth Annual International Symposium on Water Distribution Systems Analysis. Cincinnati, Ohio, August 27-30, 2006. Reston, VA: American Society of Civil Engineers. https://doi.org/10.1061/40941(247)180 